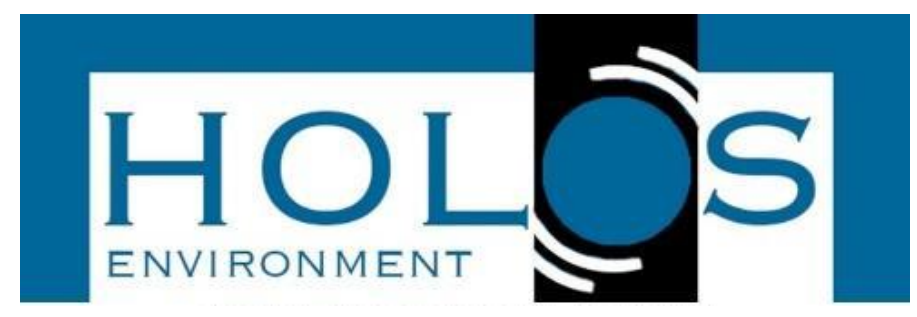

\title{
APLICAÇÃO DO ÍNDICE DE QUALIDADE DE ATERROS NOS LOCAIS DE DISPOSIÇÃO FINAL DOS RESÍDUOS SÓLIDOS URBANOS NA BACIA DO ALTO TAQUARI
}

\section{APPLICATION OF THE LANDFILL QUALITY INDEX IN THE FINAL DISPOSAL SITES OF URBAN SOLID WASTE IN THE ALTO TAQUARI BASIN}

\author{
Cleiton Oliveira dos Santos ${ }^{1,2}$; Maeli Machado do Nascimento Carelli ${ }^{2}$
}

Artigo recebido em: 09/08/2020 e aceito para publicação em: 12/02/2021.

DOI: http://doi.org/10.14295/holos.v21i2.12415

\begin{abstract}
Resumo: O gerenciamento adequado dos resíduos sólidos é uma preocupação crescente dos órgãos ambientais, pois o volume de resíduos produzidos pelas diferentes atividades antrópicas, sem destinação adequada, compromete a qualidade do meio ambiente. No Brasil, é recente a preocupação com o tratamento e a disposição final dos resíduos sólidos. Este trabalho aplicou o Índice de Qualidade de Aterros de Resíduos nos municípios da bacia do Alto Taquari no estado de Mato Grosso do Sul e a partir dos resultados, propor ações para melhoria das situações inadequadas. A aplicação do Índice de Qualidade de Aterro de Resíduos (IQR) desenvolvido pela Companhia de Tecnologia de Saneamento Ambiental do Estado de São Paulo (CETESB) foi realizada por meio de visitas nos locais de disposição final e a partir da avaliação foi perceptível que a grande maioria dos municípios ainda utilizam lixões como local de disposição final, esse fato repercutiu no baixo índice em oito cidades e apenas um aterro apresentou índice alto.
\end{abstract}

Palavras-chave: Resíduos sólidos. Gestão integrada. Indicadores ambientais.

Abstract: The adequate management of solid waste is a growing concern of environmental agencies, due the volume of waste produced by different anthropic activities, without proper disposal, compromises the environment quality. In Brazil, concern about the treatment and final disposal of solid waste is fresh. This work applied the Quality Index of Waste Landfills in the municipalities of the Alto Taquari basin in the state of Mato Grosso do Sul and, based on the results, proposing actions to improve inappropriate situations. The application of the Waste Landfill Quality Index (WLQI) developed by the Environmental Sanitation Technology Company' São Paulo state (ESTC) was carried out through visits to final disposal sites and from the assessment it was noticeable that the great most cities still use landfills as a final disposal site, this fact had repercussions on the low index in eight cities and only one landfill had a high index.

Keywords: Solid waste. Integrated management. Environmental indicators.

1 Universidade Estadual de Mato Grosso do Sul (UEMS), Dourados, MS. E-mails: (ceo.cleiton@bol.com.br, maeli.machadodonascimento@gmail.com)

2 Universidade Federal de Mato Grosso do Sul (UFMS), Pioneiros, MS. 


\section{INTRODUÇÃO}

A geração de resíduos é característica das atividades antrópicas, desde a antiguidade se intensificando após a Revolução Industrial e então começaram a surgir às primeiras preocupações com a disposição final dos resíduos, motivadas, principalmente, pela proliferação de doenças (ABRELPE, 2015).

O adequado gerenciamento dos resíduos sólidos é uma crescente preocupação dos órgãos ambientais, pois o volume de resíduos produzidos pelas diferentes atividades humanas, sem destinação apropriada, compromete a qualidade ambiental. Os serviços de gerenciamento dos resíduos sólidos compreendem a coleta, a limpeza pública, bem como a destinação final desses resíduos, e exercem um forte impacto no orçamento das administrações municipais (SANTOS et al. 2012).

O aterro sanitário é uma forma de disposição final de resíduos sólidos, baseada em critérios de engenharia e normas operacionais específicas, adequando o confinamento seguro dos resíduos impedindo eventuais danos ou riscos à saúde pública e minimizando os impactos ambientais. Analisando comparativamente as soluções sanitárias e ambientais utilizadas para a disposição final dos resíduos sólidos, os aterros sanitários são considerados a forma mais econômica em curto prazo (SANTOS et al., 2012).

Para Gimenes e Hising (2017), o aterro sanitário também deve apresentar impermeabilização do solo, tratamento do chorume, sistema de monitoramento das águas subterrâneas e ser projetado para uma vida útil de pelo menos quinze anos. Esse tipo de sistema é um tanto desafiador, principalmente para municípios pequenos, devido ao alto custo de implantação e manutenção.

Neste sentido, surge uma alternativa econômica aos municípios, diz respeito aos consórcios intermunicipais para implantação de aterro. Os consórcios intermunicipais podem ser definidos como associações entre municípios de uma dada mesorregião a fim de sanar problemas comuns compartilhando despesas e sem fins lucrativos (BATISTA, 2011). A própria PNRS estabelece em seu artigo 18, parágrafo $1^{\circ}$ e inciso $\mathrm{I}$, que os municípios que apresentarem acordos regionais terão prioridade ao acesso de recursos junto à União.

Quando se fala em formas de mensurar a qualidade ambiental é preciso partir da definição do que é qualidade ambiental, no entanto, não há um conceito amplo aplicado a esse aspecto. Mazetto (2000), traz várias percepções sobre a dificuldade 
da conceituação, mas infere que, neste caso, a qualidade pode estar relacionada à aplicação de padrões de qualidade.

Neste contexto surgem os índices de qualidade ambiental, para a construção de um índice é necessário que, primeiramente, se faça a coleta e análise de dados e então a formulação de indicadores. Esta última etapa é de suma importância já que os indicadores demonstram de forma mais clara fenômenos, eventos ou percepções. Assim, os indicadores são "um conjunto de dados ou variáveis que, submetidos a operações estatísticas, informam acerca de um determinado evento" (SOBRAL et al., 2011).

A partir do agrupamento dos indicadores são, então, formuladas as informações sínteses ou índices. O índice, como apresenta Sobral et al. (2011), aponta "por meio de um valor tanto uma relação de contiguidade com o apresentado quanto a evolução de uma quantidade em relação a uma conferência".

Pensando na avaliação das condições ambientais e sanitárias dos locais de disposição a CETESB criou um sistema de indicadores que possibilitam, a partir de métodos de pontuação, o monitoramento dessas áreas a fim de que sejam apontadas as mudanças necessárias para melhor desempenho ambiental na gestão dos resíduos sólidos urbanos. Neste sentido foram criados três índices: de Qualidade de Aterro de Resíduos (IQR); de Qualidade de Aterros de Resíduos em Valas (IQRValas); de Qualidade de Usinas de Compostagem (IQC) e têm variação de 0 a 10 pontos para classificação em duas categorias: inadequada e adequada (CETESB, 2016).

Para auxiliar a sanar os problemas referentes a essa temática nos municípios da bacia do alto Taquari, foi elaborado em 2012 o Plano de gestão integrada de resíduos sólidos para a bacia do rio Taquari que propunha ações para mitigar os aspectos ruins, além de consórcios intermunicipais para implantação de aterros sanitários (MATO GROSSO DO SUL, 2012).

Em análise do PGIRS realizada por Carelli, Nogueira e Santos (2017), foi observado que o grau de implantação das ações propostas no documento estava bastante insatisfatório, além disso, ou autores propuseram um sistema de monitoramento, por meio de indicadores, da gestão e gerenciamento dos resíduos sólidos na região.

Para a interpretação sobre a forma como a gestão integrada dos resíduos sólidos deve ser direcionada, é necessário que se faça a diferenciação entre gestão e 
gerenciamento. Alguns autores defendem como termos equivalentes, no entanto, (MERSONI; REICHERT, 2017) sugere que a principal diferença entre ambos está na ação subordinada ao termo, assim, gestão se trata "do que fazer" enquanto gerenciamento se refere a "como fazer".

Neste sentido, a gestão está intimamente relacionada à tomada de decisão e escolhas que considerem aspectos políticos, sociais, ambientais e econômicos, ao passo que gerenciamento é inerente às decisões técnicas das práticas a serem adotadas num espectro menor.

A partir da concepção da gestão, Mesquita (2007) defende que no caso da gestão integrada dos resíduos sólidos ela deve ser bastante ampla e abarcar todos os atores envolvidos de forma que a tomada de decisão considere desde os gestores centrais e locais do primeiro setor até a comunidade, ONGs, catadores e os geradores dos resíduos.

Entre os problemas ambientais relacionados à disposição inadequada dos resíduos sólidos urbanos (RSU), está o chorume. Caracterizado por ser um líquido escuro proveniente de três origens: da própria umidade do lixo; da água da matéria orgânica decorrente da composição do lixo; e pelas enzimas expelidas pelas bactérias responsáveis pela decomposição do material (SERAFIM et al., 2003).

A PNRS prevê que os planos de gestão integrada dos municípios tragam em seu conteúdo a definição dos locais escolhidos para disposição final dos resíduos sólidos que apresentem menor risco ao meio ambiente e à população. Prevê também, a priorização de acordos intermunicipais para implantação de aterros sanitários financiados junto ao governo federal.

Assim, a Lei 12.305 de 2010 define como destinação final ambientalmente adequada a "distribuição ordenada de rejeitos em aterros, observando normas operacionais específicas de modo a evitar danos ou riscos à saúde pública e à segurança e a minimizar os impactos ambientais adversos". No entanto, das aproximadamente 79 milhões de toneladas de RSU geradas anualmente no Brasil, apenas $58,7 \%$ seguem para locais adequados (ABRELPE, 2015). Percebe-se então, que grande parte desses passivos ambientais são depositados em "lixões" ou "vazadouros". Este método é caracterizado pelo depósito de resíduos a céu aberto sem nenhuma forma de tratamento ou controle ambiental, permitindo não só o acúmulo de lixo, assim como a presença e permanência de catadores vivendo tanto 
da separação e venda de materiais recicláveis como dos restos de alimentos encontrados (MERSONI; REICHERT, 2017).

Neste sentido, esse trabalho objetivou avaliar as condições ambientais e sanitárias dos locais de disposição final dos resíduos sólidos urbanos nos municípios da bacia do Alto Taquari por meio do Índice de Qualidade de Aterros de Resíduos e propor ações para melhorar aspectos considerados ruins.

\section{MATERIAL E MÉTODOS}

\section{1 Área de estudo}

A bacia do Alto Taquari está localizada na região norte do estado de Mato Grosso do Sul e abrange os municípios de Alcinópolis, Camapuã, Costa Rica, Coxim, Figueirão, Pedro Gomes, Rio Verde de Mato Grosso, São Gabriel do Oeste e Sonora (Figura 1). Segundo dados da Secretaria de Estado de Meio Ambiente e Desenvolvimento Econômico (SEMADE, 2015) o município polo da região é São Gabriel do Oeste e tem a economia baseada, principalmente, no setor de serviços com $53 \%$ do PIB regional e na agropecuária com 34\%. A taxa média de urbanização é de $84 \%$ tendo população total de 136.904 pessoas e população urbana de 115.642 (IBGE, 2010). Entenda-se que a bacia do Alto Taquari (BAT) não abrange os municípios de Ladário e Corumbá, pois ambos estão localizados à parte baixa do rio, na região em que ele deságua no rio Paraguai, no entanto integraram o Plano de Gestão Integrada realizado em 2012.

Durante a realização do diagnóstico no Plano de Gestão Integrada de Resíduos Sólidos para a bacia do Alto Taquari (PGIRS-BAT) SEMADE, (2012), grande parte dos municípios apresentavam condições inadequadas nos locais de disposição final dos resíduos, além disso, havia catadores, crianças, animais e até moradores como mostra o quadro 2 . 
Figura 1 - Mapa de localização da área de estudo

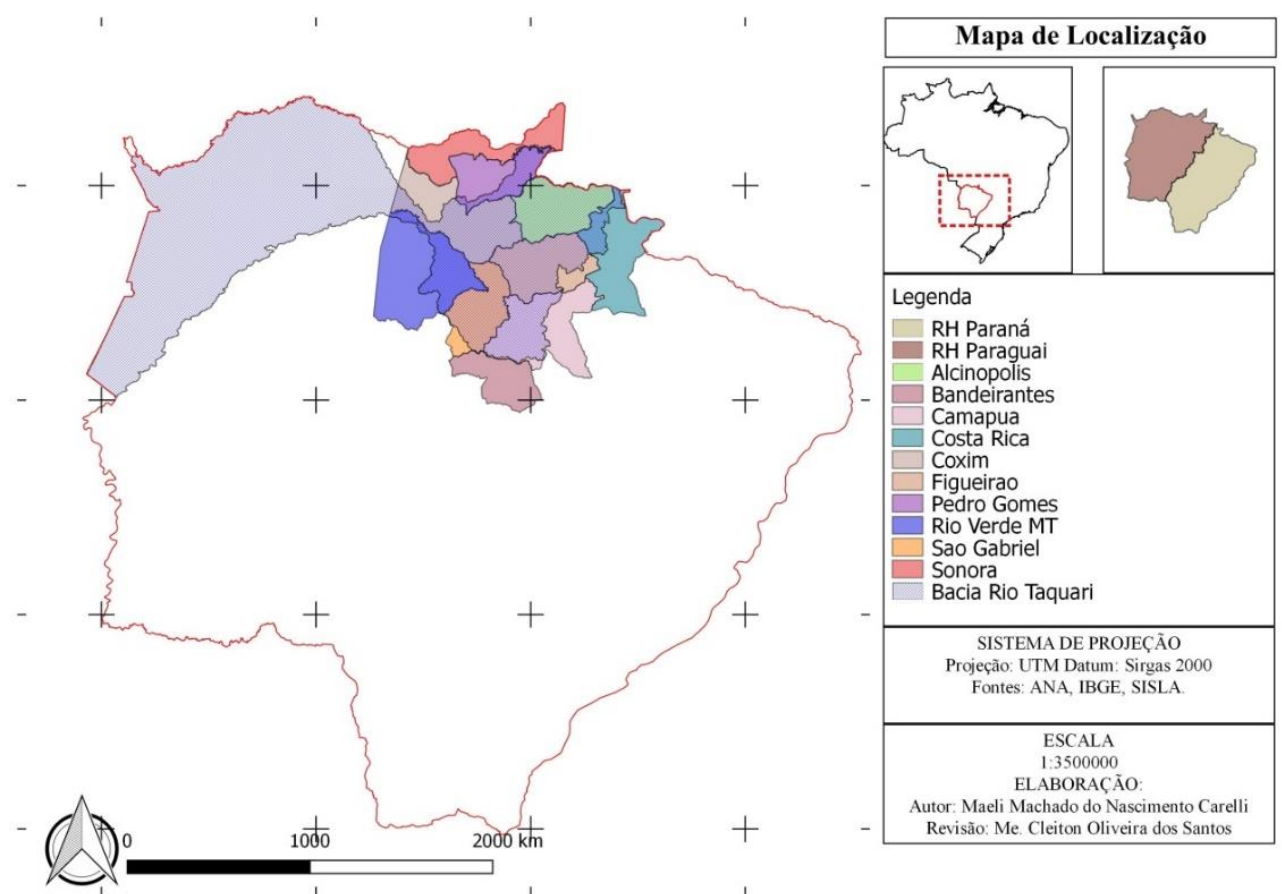

Fonte: Autoria própria

Quadro 1 - Situação dos locais de disposição final dos RSU dos municípios pertencentes à BAT em 2012

\begin{tabular}{|c|c|c|c|c|c|}
\hline Município & Tipo & $\begin{array}{l}\text { Distância } \\
\text { do núcleo } \\
\text { urbano }\end{array}$ & $\begin{array}{c}\text { Presença de } \\
\text { Catadores no } \\
\text { momento da visita }\end{array}$ & $\begin{array}{c}\text { Presença } \\
\text { de } \\
\text { moradores }\end{array}$ & $\begin{array}{c}\text { Presença } \\
\text { de aves e } \\
\text { animais }\end{array}$ \\
\hline Alcinópolis & Aterro sanitário & $>500 \mathrm{~m}$ & Não & Não & Não \\
\hline Camapuã & Lixão & $>500 \mathrm{~m}$ & Não & Não & Sim \\
\hline Costa Rica & Lixão & $>500 \mathrm{~m}$ & Não & Não & Não \\
\hline Coxim & $\begin{array}{l}\text { Aterro } \\
\text { controlado }\end{array}$ & $>500 \mathrm{~m}$ & $\operatorname{Sim}(12)$ & Não & Sim \\
\hline Figueirão & $\begin{array}{l}\text { Aterro } \\
\text { controlado }\end{array}$ & $>500 \mathrm{~m}$ & $\operatorname{Sim}(4)$ & Não & Sim \\
\hline Pedro Gomes & Lixão & $>500 \mathrm{~m}$ & $\operatorname{Sim}(6 / 1$ criança $)$ & Não & Sim \\
\hline Rio Verde de MT & Lixão & $>500 \mathrm{~m}$ & $\operatorname{Sim}(5)$ & $\operatorname{Sim}(5)$ & Sim \\
\hline São Gabriel do Oeste & Lixão & $<500 \mathrm{~m}$ & Não & Não & Sim \\
\hline Sonora & $\begin{array}{l}\text { Aterro } \\
\text { controlado }\end{array}$ & $>500 \mathrm{~m}$ & $\operatorname{Sim}(2)$ & Não & Não \\
\hline
\end{tabular}

Fonte: Adaptado do PGIRS-BAT (2012).

Ainda de acordo com o Plano de Gestão Integrada de 2012, foram propostos alguns arranjos intermunicipais para consórcio de aterros sanitários, que consideraram a distância entre os municípios e o local de disposição final de forma que fosse viável economicamente. Assim, a tabela 1 apresenta os acordos propostos à época. A tabela 2 apresenta a relação dos municípios e respectivas siglas. 
Tabela 1 - Consórcios intermunicipais propostos no PGIRS-BAT para implantação de aterro sanitário.

\begin{tabular}{cccc}
\hline Consórcio 1 & Consórcio 2 & Consórcio 3 & Consórcio 4 \\
\hline Corumbá & Alcinópolis & Sonora & Camapuã \\
Ladário & Figueirão & Coxim & São Gabriel do Oeste \\
& & Pedro Gomes & Bandeirantes \\
& & Rio Verde de MT & \\
\hline
\end{tabular}

Fonte: PGIRS-BAT (2012).

Tabela 2 - Relação dos municípios da BAT e siglas

\begin{tabular}{ll}
\hline \multicolumn{1}{c}{ Município } & \multicolumn{1}{c}{ Sigla } \\
\hline Camapuã & $\mathrm{CA}$ \\
Costa Rica & $\mathrm{CR}$ \\
Coxim & $\mathrm{CX}$ \\
Figueirão & $\mathrm{FI}$ \\
Pedro Gomes & $\mathrm{PG}$ \\
Rio Verde de MT & $\mathrm{RI}$ \\
São Gabriel do Oeste & SG \\
Sonora & SO \\
\hline
\end{tabular}

\subsection{Métodos de avaliação e coleta dos dados}

Para aplicação do IQR foram realizadas visitas pontuais nos locais de disposição final dos RSU nos municípios da BAT entre os meses de maio e outubro de 2018, dessa forma a avaliação teve início no dia quinze de maio em Sonora e dia dezesseis em Pedro Gomes. Os municípios de Costa Rica, Alcinópolis e Figueirão foram visitados no dia vinte e quatro de agosto, Camapuã e São Gabriel do Oeste dia vinte e cinco de setembro e, por fim, Rio Verde de Mato Grosso e Coxim nos dias nove e dezesseis de outubro, respectivamente.

O IQR é dividido em 3 partes que se desdobram em itens e sub-itens de avaliação e totalizam no máximo 130 pontos quando há recebimento de resíduos industriais e 100 pontos quando não há (CETESB, 2016).

A primeira parte do índice envolve as características físicas, estruturas de apoio e estruturas de proteção ambiental. A segunda parte, que avalia outras informações, traz sub-itens acerca da ocorrência de queima dos resíduos, presença de catadores, presença de aves, animais e moscas, além do recebimento de resíduos industriais e resíduos não autorizados. Na terceira etapa são avaliadas as características da área em relação à distância de corpos hídricos e de centros urbanos, possíveis restrições legais do uso do solo e o tempo de vida útil do local.

Dos nove municípios bacia do rio Taquari que participaram do Plano de gestão integrada, apenas Alcinópolis não contava com um local de disposição final dos resíduos no próprio município, pois o antigo aterro sanitário municipal já teve sua 
capacidade máxima atingida. O município realiza, por meio de cooperativa de catadores, a triagem dos resíduos e envia o rejeito para um aterro sanitário no município de Três Lagoas (MS), portanto não foi possível aplicar o IQR.

A equação 1 mostra o cálculo para categorização dos aterros e a partir do resultado os locais foram classificados de acordo com os valores e respectivas condições demonstrados na tabela 3.

$I Q R=\frac{\sum t}{10}$

Onde, IQR designa o índice de qualidade dos aterros; e $\Sigma_{\mathrm{t}}$ a soma de todos os itens avaliados.

Tabela 3 - Categorias do IQR

\begin{tabular}{cc}
\hline IQR & AVALIAÇÃO \\
\hline 0 a 7,0 & Condições inadequadas \\
7,1 a 10 & Condições adequadas \\
\hline
\end{tabular}

Para cálculo do custo dos aterros foi utilizado o Estudo sobre os aspectos econômicos e financeiros da implantação de aterros sanitários (ABETRE, 2007). Os valores foram corrigidos até dezembro de 2015 pelo Índice Nacional do Custo da Construção (FGV, 2015) e por regressão linear (equação 2) para adaptação à capacidade de geração de resíduos dos municípios da sub-bacia.

$Y=a x+b$

Onde $Y$ representa a variável explicada ou dependente; $a$ é a constante que intercepta a reta; $x$ a variável independente; e $b$ é outra constante que representa 0 declive da reta. Muito utilizado para determinação e previsão de custos, o método de regressão linear pode ser utilizado tanto para estimar os valores de uma variável, com base nos valores de outra variável conhecida, serve também para explicar os valores de uma variável com base nos valores da outra e ainda prenunciar futuros valores de uma variável. Assim, a regressão linear determina o efeito da variável explicada $X$ sobre a dependente $\mathrm{Y}$ e a partir do ajuste de $\mathrm{R}^{2}$, pode-se denotar que quanto mais próximo a 1 for o valor de $\mathrm{R}^{2}$ mais confiável ou melhor será o ajuste (SELL, 2005).

A tabela 4 apresenta os valores médios cobrados por empresas para transporte, tratamento e disposição final dos resíduos sólidos domésticos no estado 
de Mato Grosso do Sul. Para cálculo do custo por viagem, foi considerada a transferência para aterro licenciado na cidade de Três Lagoas.

Tabela 4 - Valores para transporte e destinação final dos resíduos em aterro sanitário no município de Três Lagoas

\begin{tabular}{l|lc|c}
\hline \multicolumn{1}{c|}{ Descrição } & \multicolumn{2}{c|}{ Unidade } & Valor unitário \\
\hline Locação de contêiner & (1) Unidade & $\mathrm{R} \$ 1.000,00$ \\
\hline $\begin{array}{l}\text { Transporte de contêiner com carga de } \\
\text { resíduos sólidos classe II (máx.28 }\end{array}$ & \multicolumn{2}{|c|}{ (1) $\mathrm{Km}$} & $\mathrm{R} \$ 5,50$ \\
t/viagem) & & \\
\hline $\begin{array}{l}\text { Tratamento e disposição final de rs } \\
\text { classe II em aterro sanitário }\end{array}$ & & & \\
licenciado & & Tonelada & $\mathrm{R} \$ 70,00$ \\
\hline
\end{tabular}

\section{RESULTADOS E DISCUSSÃO}

\subsection{Situação geral dos municípios}

O gráfico 1 apresenta os resultados totais do IQR nos oito municípios avaliados, e Costa Rica é o único que conta com aterro sanitário em funcionamento, fato que se refletiu no resultado do índice $(9,0)$ e foi a única situação adequada verificada na bacia. Os demais municípios apresentaram índice bem baixo variando entre 1,2 em Rio Ver de Mato Grosso e 2,8 em São Gabriel do Oeste.

Figura 2 - Resultado do IQR nos locais de disposição final dos RSU na sub-bacia do rio Taquari

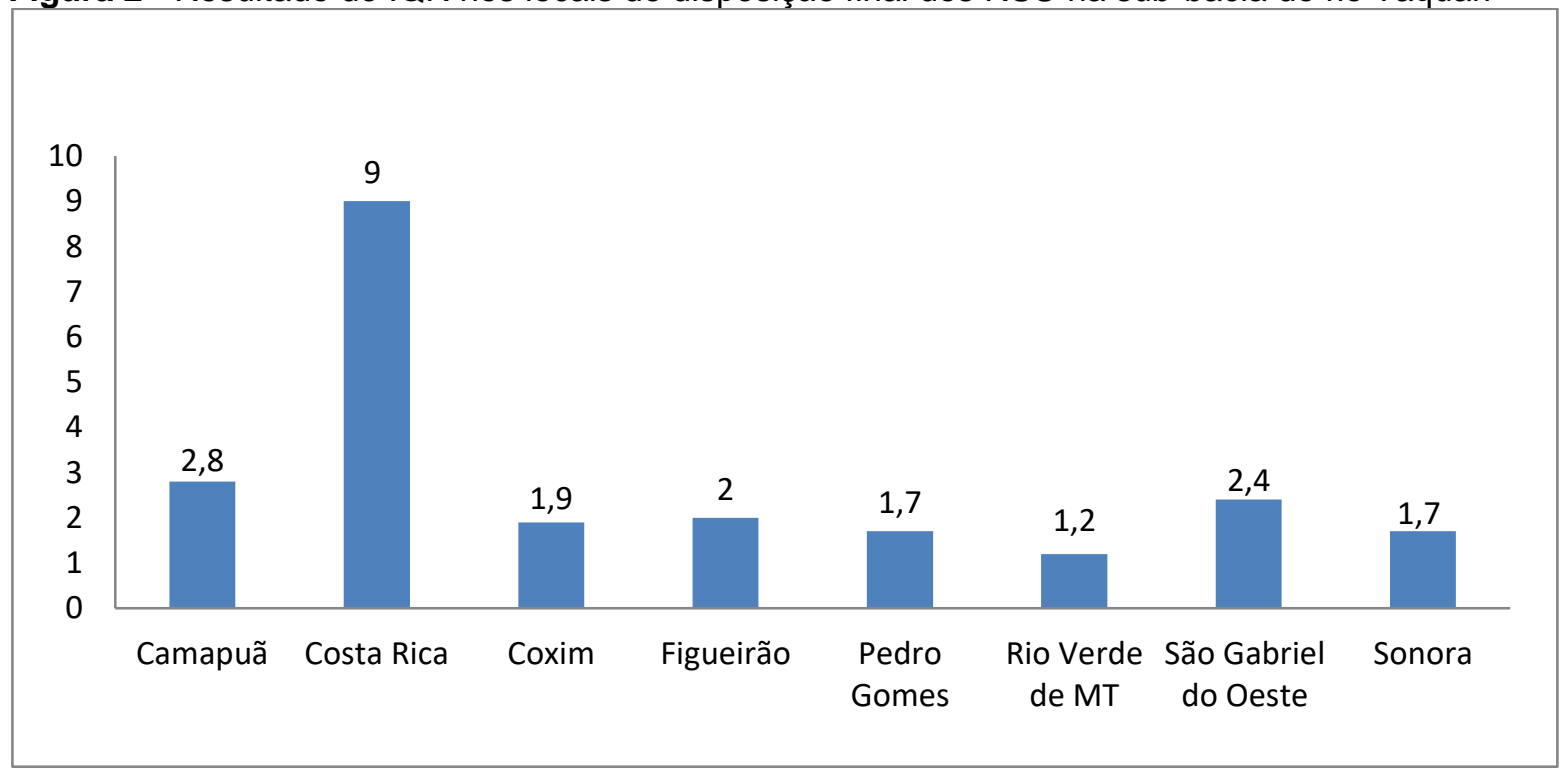

Costa Rica também é o único dos municípios com mudança positiva em relação ao local de disposição final dos resíduos desde o diagnóstico realizado em 2012 no 
PGIRS-BAT, pois, inutilizou o antigo lixão e implantou aterro sanitário. Coxim, Figueirão e Sonora constavam à época com aterro controlado, no entanto, não apresentaram recobrimento dos resíduos de forma adequada para essa categoria. Camapuã, Pedro Gomes, Rio Verde de Mato Grosso e São Gabriel do Oeste mantiveram o mesmo panorama encontrado anteriormente.

Outro aspecto que não obteve melhora significativa foi em relação à presença de catadores nos locais, as únicas alterações se devem à Camapuã, que não apresentava nenhum catador em 2012 sendo observada a presença durante a realização deste trabalho, e à Pedro Gomes que apesar de ainda apresentar catadores, não foi observada a presença de crianças no local. O gráfico 2 mostra o percentual de municípios que ainda apresentavam catadores nos locais de disposição final dos resíduos nos momentos das visitas, esse quadro foi observado em Camapuã, Coxim, Pedro Gomes, Rio Verde de Mato Grosso e Sonora (62\%).

Figura 3 - Percentual de municípios que apresentaram ou não catadores nos locais de disposição final dos RSU

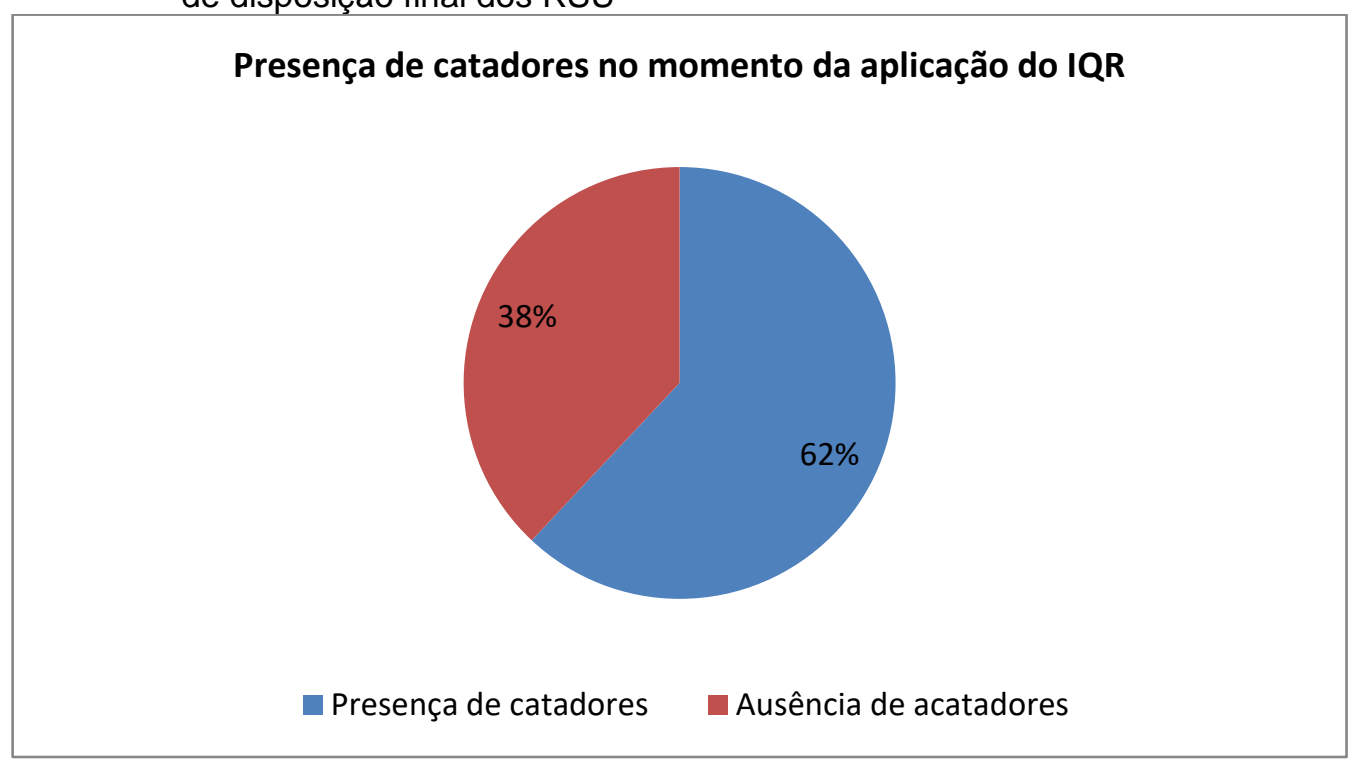

Os aspectos menos atendidos foram à drenagem provisória e definitiva das águas pluviais e a falta de drenagem dos gases. No entanto, o sub-item responsável por baixar o índice foi a falta de impermeabilização adequado do solo, já que tem peso 10 e apenas Costa Rica apresentou situação favorável.

A falta de isolamento físico adequado também tem forte influência no resultado, isso porque essa condição apresentou relação com outros dois problemas: o recebimento de resíduos não autorizados e a presença de catadores. Apenas em um 
dos lixões onde o isolamento físico está inadequado, não foi verificada a presença de catadores, porém, todos recebiam resíduos não autorizados.

Os sub-itens mais atendidos foram em relação à proximidade entre o local e corpos hídricos superior a 200 metros e a proximidade superior a $500 \mathrm{~m}$ de núcleos urbanos. A única exceção neste último foi constatada em São Gabriel do Oeste onde o avanço da urbanização já ultrapassou esse limite. Outro aspecto que foi considerado atendido em todos os municípios foi à vida útil da área superior a cinco anos, porém essa condição não reflete estratégias de planejamento - excetuando Costa Rica - e sim a falta de opções economicamente viáveis aos municípios.

As principais ações corretivas devem ser voltadas para o isolamento físico e visual, adequação à frente de descargas e impermeabilização do solo. Para isolamento físico, as técnicas mais empregadas são barreiras físicas constituídas por mourões e arames, além disso, é ideal a implantação de barreira vegetal com vistas à adequação do isolamento visual e retenção de materiais leves, como papel e sacolas plásticas, dentro do perímetro do lixão.

Para os municípios de Pedro Gomes, Sonora e Rio Verde de MT é necessária a adequação à frente de descargas de forma de forma que as vias de acesso permitam o trânsito dentro dos locais sob quaisquer condições climáticas. Quanto aos aspectos relacionados à compactação, recobrimento, cobertura, proteção vegetal, nivelamento e homogeneidade da superfície, primeiramente devem ser trabalhados a gestão integrada para diminuição da quantidade de resíduos que chegam aos locais, logo, a quantidade de material necessário para recobrimento e nivelamento também seria menor.

Mesmo sendo o elemento mais desafiador no tocante à adequação, a impermeabilização do solo pode ser feita de várias formas, as mais recorrentes são: solo compactado; geomembranas; emulsões asfálticas; concreto; membranas de bentonita; solo-cimento; misturas de areia e bentonita; polietileno clorosulforado; entre outros.

A presença de catadores e o recebimento de resíduos não autorizados são evitados a partir do isolamento físico, construção e operação de portaria com vigilância. Já a queima, ocorrência de moscas e presença de aves pode ser inibida com o recobrimento adequado e periódico dos resíduos. O gráfico 3 demonstra a evolução no IQR se os municípios adequassem os itens discutidos e se empregassem formas de impermeabilização do solo. 
Figura 4 - Comparativo entre o IQR encontrado e a evolução com emprego de ações corretivas

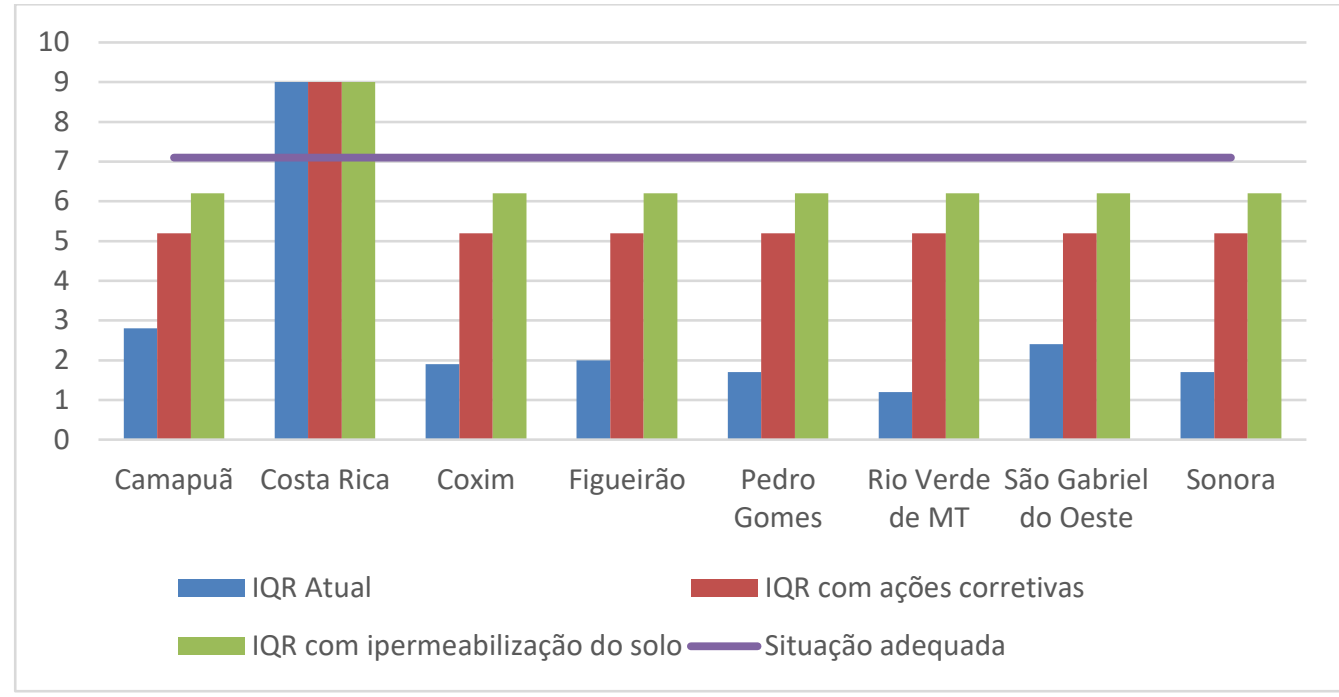

O primeiro aspecto que deve ser trabalhado pelas administrações dos municípios da bacia é a melhoria da gestão integrada dos resíduos, pois foi perceptível que não há estruturação adequada. Castilhos Júnior (2003) apresenta um exemplo de estrutura viável para municípios de pequeno porte (Figura 5).

Figura 5 - Estrutura de gestão integrada para municípios de pequeno porte.

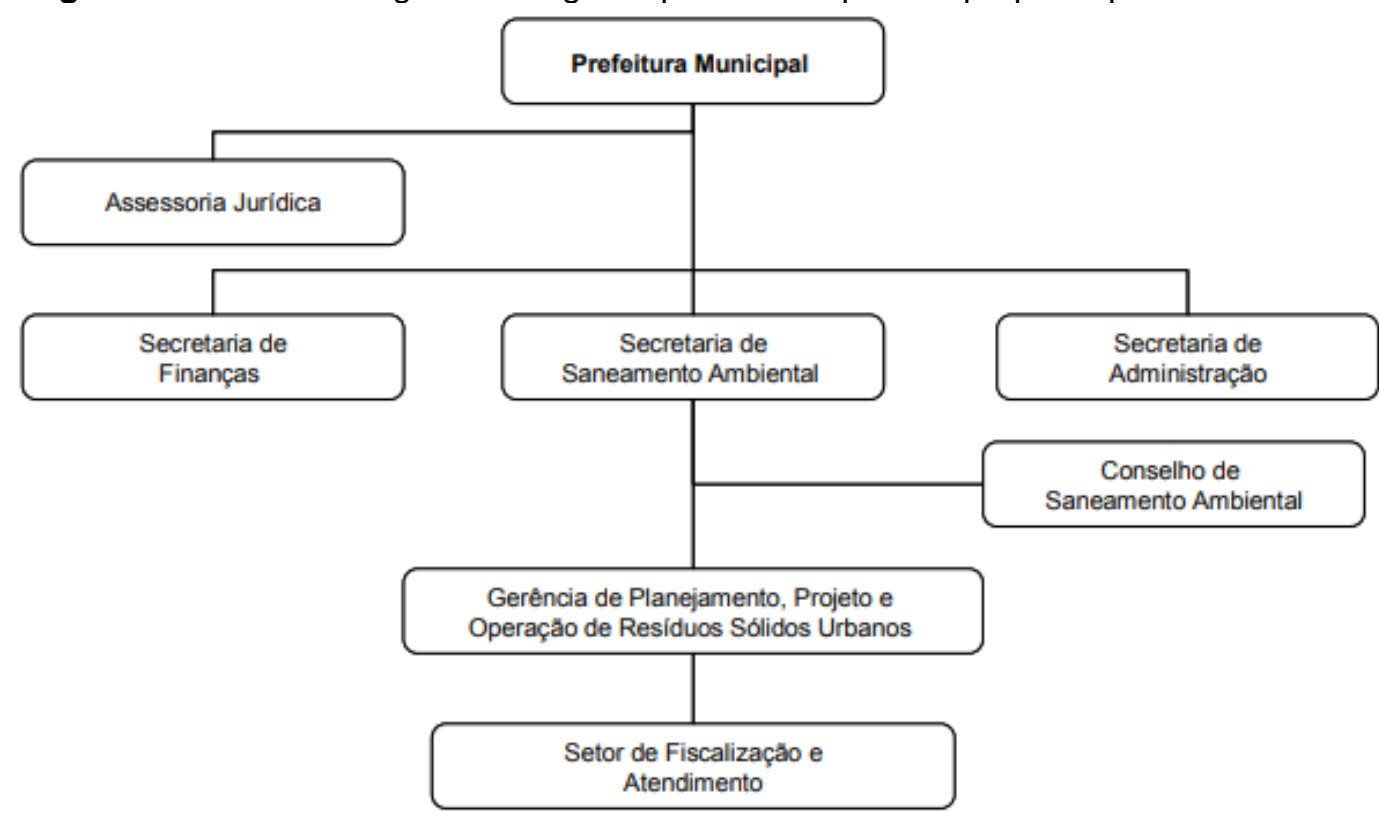

Fonte: Castilhos Júnior (2003)

A partir da consolidação do sistema de gestão integrada, deve-se priorizar o que o autor denomina de ações de ordem decrescente, isto é iniciar o processo com "a redução na fonte, o reaproveitamento, o tratamento e a disposição final". Nota-se 
que as medidas em relação aos locais de disposição final não devem ser isoladas e tampouco ser priorizadas em detrimento dos demais aspectos.

Neste caso, um exemplo a ser seguido é o município de Rio Verde de MT, antes mesmo da implantação de aterro sanitário implantou coleta seletiva e a usina de triagem dos resíduos (UTR) juntamente com a "Associação de Catadores de Materiais Recicláveis de Rio Verde de MT". Assim, diminui a quantidade de resíduos que chegam até o local de disposição final aumentando a vida útil da área.

Para melhora efetiva dos resultados do IQR, seria ideal a implantação de aterros sanitários ou transferência dos resíduos para aterros licenciados. A tabela 3 apresenta os custos para implantação e operação de um aterro sanitário com capacidade de 100 t. $\mathrm{dia}^{-1}$. No entanto, pelos arranjos propostos no PGIRS-BAT (SEMAD, 2012), um aterro deste tamanho seria muito maior do que a capacidade de geração de RSU entre os municípios consorciados (gráfico 5), sendo assim, os valores foram corrigidos para aterros com capacidade de 10 t/dia, 25 t.dia ${ }^{-1}$., 50 t.dia ${ }^{-1}$., 100 t. dia ${ }^{-1}$., 800 t. dia ${ }^{-1}$., 2.000 t. dia ${ }^{-1}$. e estão apresentados no gráfico 4.

Tabela 5- Custo total para implantação de aterro sanitário com capacidade de 100 t/dia

\begin{tabular}{lc}
\hline \multicolumn{1}{c}{ Etapa do aterro } & Custo \\
\hline Pré-implantação & $\mathrm{R} \$ 1.138 .914,78$ \\
Implantação & $\mathrm{R} \$ 4.999 .229,18$ \\
Operação & $\mathrm{R} \$ 3.045 .456,00$ \\
Encerramento & $\mathrm{R} \$ 911.501,54$ \\
Pós-encerramento & $\mathrm{R} \$ 6.016 .569,09$ \\
Custo Total & $\mathbf{R} \$ \mathbf{1 0 . 4 2 9 . 3 5 5 , 3 3}$ \\
\hline
\end{tabular}

Fonte: ABETRE/FGV, 2007 (corrigido pelo INCC até 12/2015).

A partir da equação de regressão linear $Y=1.946,8+58,994 . X$ e seguindo os arranjos de três aterros para a região, os municípios de Alcinópolis, Figueirão, teriam gasto estimado de operação de $\mathrm{R} \$ 1.086,09$ por tonelada depositada em um aterro com capacidade para receber 10 toneladas diárias de RSU. Coxim, Pedro Gomes, Rio Verde de MT e Sonora gastariam $\mathrm{R} \$ 4.520,15$ por tonelada depositada considerando a manutenção de um aterro com capacidade de 50 toneladas diárias. Por fim, Camapuã e São Gabriel do Oeste teriam um gasto, juntamente com Bandeirantes, de $\mathrm{R} \$ 2.445,91$ por tonelada depositada em aterro com capacidade para 25 toneladas diárias. 
Figura 6 - Geração estimada de RSU em t/dia nos municípios da bacia do rio Taquari

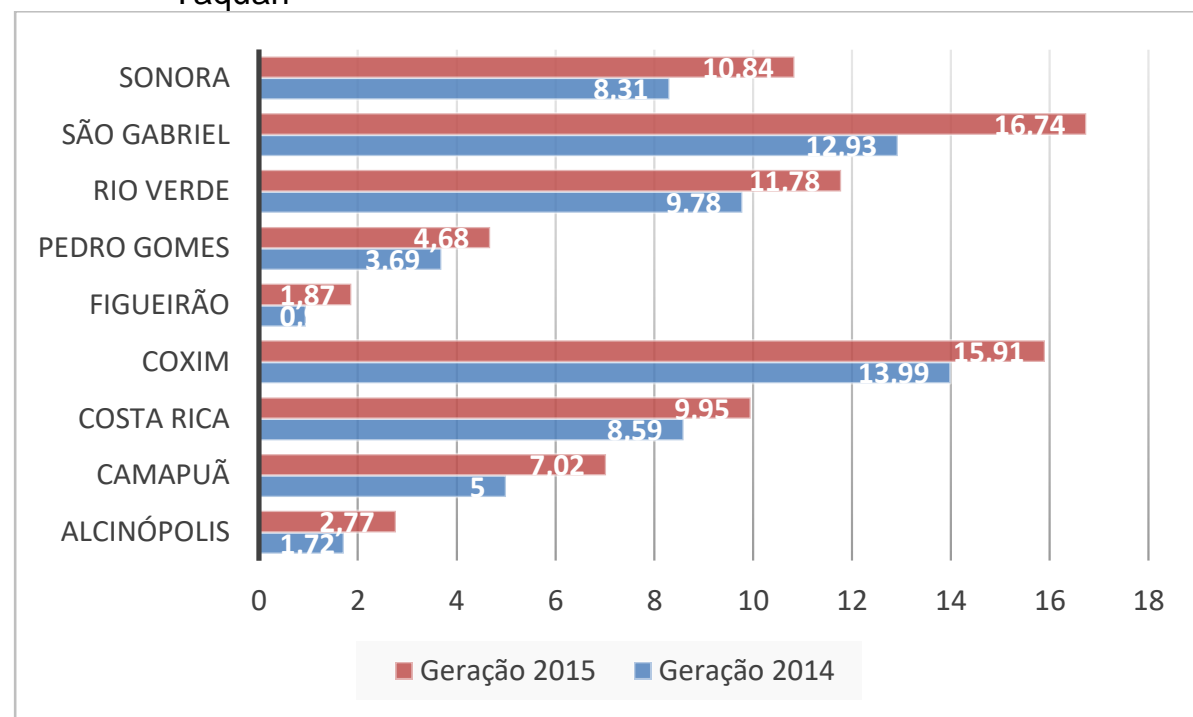

Fonte: SNIS (2015); Plano Estadual de Resíduos Sólidos - MS (2014).

Para comparação da medida mais viável economicamente, os valores propostos no orçamento levantado pelo município de Coxim, foram aplicados à quilometragem de distância entre cada município e Três Lagoas e a quantidade mensal de resíduos sólidos urbanos gerados nos município para transporte e disposição final. Os valores foram comparados ao investimento necessário para operação mensal dos aterros consorciados e o gráfico 5 apresenta os resultados.

Figura 7 - Comparativo entre os custos de operação dos aterros e os custos para transferência e disposição final dos RSU em aterro licenciado no município de Três Lagoas

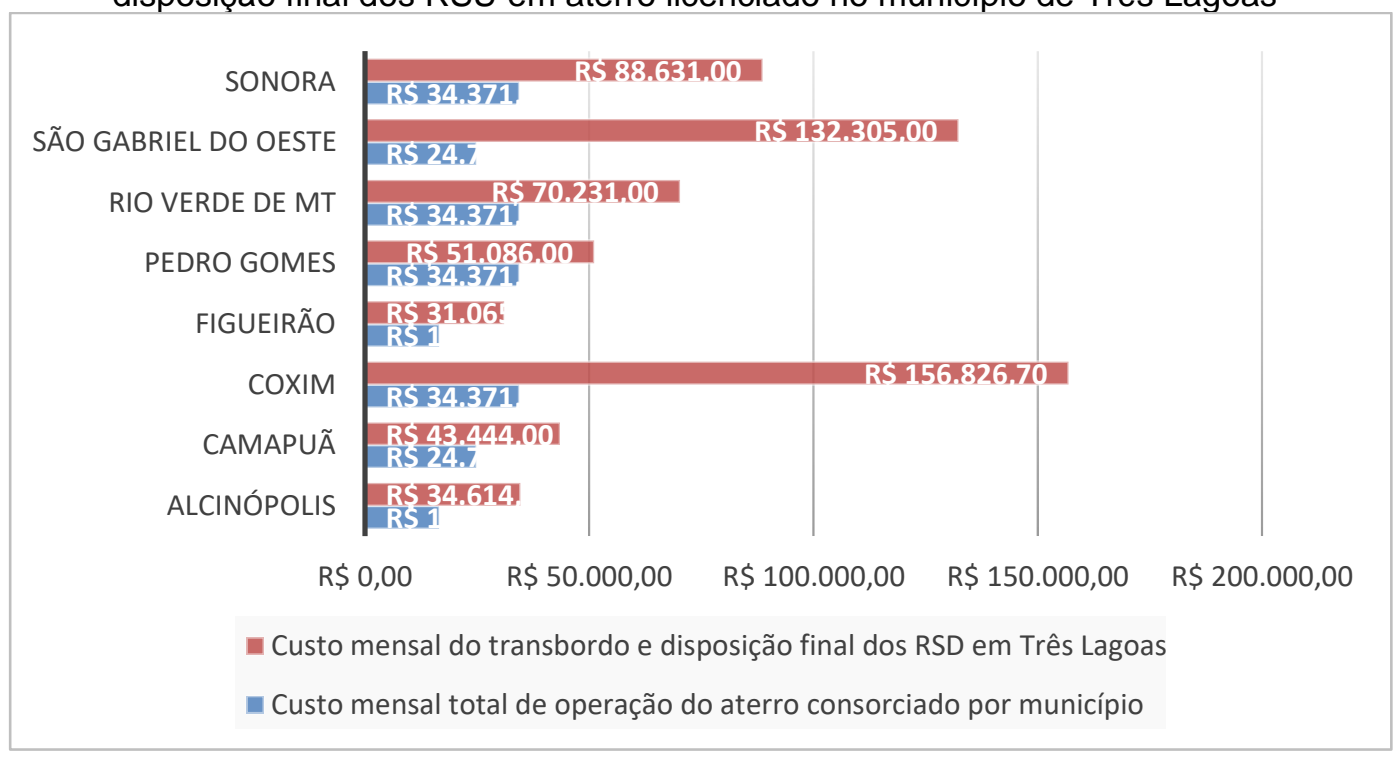

É notável a grande diferença entre os gastos estimados para operação dos aterros consorciados e o translado para disposição final dos resíduos. Desta forma é 
nítida a vantagem da implantação de aterro sanitário consorciado para todos os municípios, como diferença maior em Coxim, São Gabriel do Oeste e Sonora, pois além de apresentarem as maiores quantidades de resíduos, são os que estão mais distantes de Três Lagoas.

O Tribunal de Contas do Estado - MS (2016) publicou um levantamento dos Indicadores de resíduos sólidos nos municípios de Mato Grosso do Sul e neste documento sugeriu os valores que deveriam ser investidos per capita na gestão e disposição final dos RSU em cada município. O gráfico 6 mostra que a maioria das cidades investe menos do que o recomendado pelo tribunal e em Alcinópolis, Coxim e São Gabriel do Oeste os valores continuariam abaixo mesmo com a implantação dos aterros consorciados, fato que denota a viabilidade econômica da adequação deste aspecto em relação à PNRS. A média sugerida pelo TCE-MS para investimento per capita ficou em $R \$ 5,66$ por hab./mês, com variação maior para Figueirão onde o valor sugerido foi de $R \$ 10,16$ por hab./mês e para Coxim com recomendação de $R \$$ 2,86 por hab./mês.

Figura 8 - Comparação entre os valores investidos per capita, com e sem aterro, pelos municípios e o investimento sugerido pelo TCE-MS

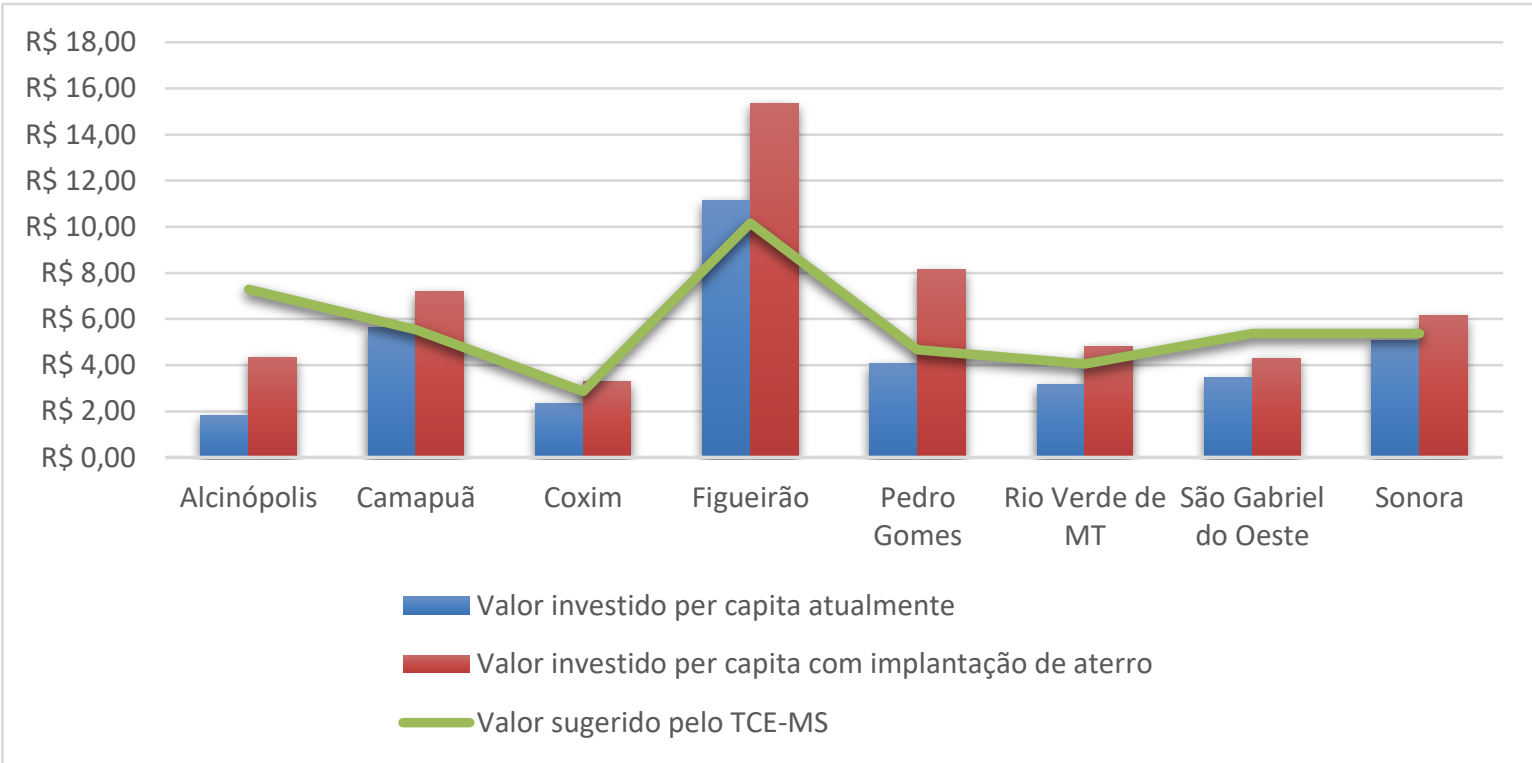

\section{CONCLUSÕES}

O emprego do índice IQR se mostrou bastante útil na avaliação das condições ambientais e sanitárias dos locais de disposição final dos resíduos nos municípios da bacia do rio Taquari. A partir da aplicação do índice foi possível verificar um alto índice 
de inadequação na qualidade da gestão de RSU, excetuando-se Costa Rica. Os demais municípios apresentaram condições bastante inadequadas com índice variando entre 1,2 e 2,8 .

O principal aspecto que influenciou esse resultado foi à persistência do uso de lixões como local de disposição final dos RSU, além disso, não possuem estruturas mínimas seja, portaria, isolamento físico adequado e cobertura adequada dos resíduos, assim como presença a de catadores.

A partir da análise, a implantação dos aterros sanitários consorciados se mostrou economicamente viável como alternativa aos lixões e à destinação dos resíduos para aterro em outro município. Além do benefício econômico, os municípios se adequariam à Política Nacional dos Resíduos Sólidos e mitigariam os impactos ambientais causados pela disposição inadequada dos resíduos.

\section{AGRADECIMENTOS}

Agradecemos ao Consórcio Intermunicipal para o Desenvolvimento Sustentável da Bacia Hidrográfica do Rio Taquari - COINTA e toda sua equipe pelo apoio logístico na realização desse trabalho.

\section{REFERÊNCIAS}

ABETRE, Associação Brasileira de Empresas de Tratamento de Resíduos. Estudo sobre os aspectos econômicos e financeiros da implantação de aterros sanitários. Rio de Janeiro: FGV Projetos, 2007. Disponível em: http://br456.teste.website/ abetre70/wpcontent/uploads/2019/11/FGV-Aterros-Sanitarios-Estudo.pdf. Acesso em: 04 abr. 2018.

ABRELPE - Associação. Associação Brasileira de Empresas de Limpeza Pública e Resíduos Especiais. Panorama dos resíduos sólidos no Brasil, 2015.

BATISTA, S.; VECCHIA, R.. Guia de consórcios públicos. Caixa Econômica Federal, 2011.

BRAGA, M.C.B.; RAMOS, S.I.P. Desenvolvimento de um modelo de banco de dados para sistematização de programas de gerenciamento integrado de resíduos sólidos em serviços de limpeza pública. Engenharia Sanitaria e Ambiental, v. 11, n. 2, p. 162-168, 2006. http://dx.doi.org/10.1590/S1413-41522006000200009

CARELLI, M.M.N.; NOGUEIRA, W.A.V. \& SANTOS C.O.S. Avaliação da gestão integrada de resíduos sólidos no contexto de sub-bacias hidrográficas. In: CONGRESSO

BRASILEIRO DE GESTÃO AMBIENTAL, 7., 2017. [Anais...]. Campo Grande, MS, 2017.

Holos Environment (2021), 21 (2): 264-281. 279 
CASTILHOS JUNIOR, A.B. Resíduos sólidos urbanos: aterro sustentável para municípios de pequeno porte. Rio de Janeiro: ABES, 2003.

CETESB - Companhia de Tecnologia de Saneamento Ambiental do Estado de São Paulo. Inventário estadual de resíduos sólidos urbanos, 2016. Disponível em:

https://cetesb.sp.gov.br/solo/wp-content/uploads/sites/18/2013/12/inventario-residuossolidos-2016.pdf. Acesso em: 24 abr. 2018.

CONAMA, Conselho Nacional de Meio Ambiente. Resolução CONAMA n 01, de 23 de janeiro de 1986, Dispõe sobre critérios básicos e diretrizes gerais para a avaliação de impacto ambiental. Ministério do Meio Ambiente, Diário Oficial da União, 17 de fev. 1986.

FGV. Fundação Getúlio Vargas. Índice nacional de custo da construção, 2015.

GIMENES, E.; HISING, E. Aterros sanitários, aterros controlados e lixões: entenda o destino do lixo no Paraná. São Paulo, 2017. Disponível em:

https://cetesb.sp.gov.br/biogas/2017/08/01/aterros-sanitarios-aterros-controlados-e-

lixoesentenda-o-destino-do-lixo-no-paranal. Acesso em: 20 abr. 2018

IBGE. Instituto Brasileiro de geografia e Estatística. Censo demográfico, 2010.

MATO GROSSO DO SUL. Secretaria de Estado e meio Ambiente, do Planejamento, da ciência e Tecnologia. Plano de Gestão Integrada de Resíduos Sólidos para a sub-bacia do rio Taquari. Campo Grande: Secretaria de Estado e meio Ambiente, do Planejamento, da ciência e Tecnologia, 2012. 236 p. Disponível em:

http://cointams.com.br/index.php/publicacoes/20-plano-de-gestao-integrada-de-residuossolidos-para-a-sub-bacia-do-rio-taquari. Acesso em: 10 fev. 2018.

MATO GROSSO DO SUL. Secretaria de Estado e meio Ambiente, do Planejamento, da ciência e Tecnologia. Plano Estadual de Resíduos Sólidos de Mato Grosso do Sul (PERS-MS). Campo Grande: Secretaria de Estado e meio Ambiente, do Planejamento, da ciência e Tecnologia, 2014. Disponível em:

https://sites.google.com/site/persmsdmtr/persms-versao-final. Acesso em: 15 fev. 2018.

MAZETTO, F.A.P. Qualidade de vida, qualidade ambiental e meio ambiente urbano: breve comparação de conceitos. Sociedade \& Natureza, v. 12, n. 24, 2000.

MERSONI, Cristina; REICHERT, Geraldo Antônio. Comparação de cenários de tratamento de resíduos sólidos urbanos por meio da técnica da Avaliação do Ciclo de Vida: o caso do município de Garibaldi, RS. Eng. Sanit. Ambient., Rio de Janeiro , v. 22, n. 5, p. 863-875, out. 2017. Disponível em: http://www.scielo.br/scielo.php?script=sci arttext\&pid=S1413$41522017000500863 \&$ Ing=en\&nrm=iso. Acesso em: 09 Aug. 2018.

https://doi.org/10.1590/s1413-41522017150351.

MESQUITA, J.M. Gestão integrada de resíduos sólidos: mecanismo de desenvolvimento limpo aplicado a resíduos sólidos. Rio de Janeiro: IBAM, 2007.

SANTOS, A.A.F. Índice de qualidade de aterro de resíduos (IQR), como subsídio para avaliar o sistema de disposição final do município de Anápolis-Go. Scientia Plena, v. 8, n. 10, 2012.

SELL, I. Utilização da regressão linear como ferramenta de decisão na gestão de custos. In: CONGRESSO BRASILEIRO DE CUSTOS-ABC, 2005. [Anais...], 2005. 
SEMADE, Secretaria de Estado de Meio Ambiente e Desenvolvimento Econômico. Estudo da dimensão territorial do Estado de Mato Grosso do Sul: regiões de planejamento. Campo Grande: SEMADE, 2015. Disponível em: http://www.semagro.ms.gov.br/wpcontent/uploads/sites/157/2017/06/estudo dimensao territorial 2015.pdf. Acesso em: 10 jun. 2018.

SERAFIM, A.C.; GUSSAKOV, K.C.; SILVA, F.; CONEGLIAN, C.M.; BRITO, N.D.; SOBRINHO, G.D.; \& PELEGRINI, R. Chorume, impactos ambientais e possibilidades de tratamentos. In: FÓRUM DE ESTUDOS CONTÁBEIS, 3., 2003. [Anais...]. Rio Claro: Centro Superior de Educação Tecnológica, p. 6-7, 2003.

SOBRAL, A.; FREITAS, C.M.D.; PEDROSO, M.D.M.; \& GURGEL, H.D.C. Definições básicas: dado, indicador e índice. In: BRASIL. Ministério da Saúde. Guia básico para construção de indicadores. Brasília: Ministério da Saúde, 2011, p. 25-52.

TRIBUNAL DE CONTAS DO MATO GROSSO DO SUL. Indicadores de resíduos sólidos nos municípios de MS. Campo Grande: TCE-MS, 2016. 